\title{
Suffering from Loneliness Indicates Significant Mortality Risk of Older People
}

\author{
Reijo S. Tilvis, ${ }^{1,2}$ Venla Laitala V, ${ }^{1}$ Pirkko E. Routasalo, ${ }^{2}$ and Kaisu H. Pitkälä2,3 \\ ${ }^{1}$ Clinics of Internal Medicine and Geriatrics, Helsinki University Central Hospital, BOX 340, 00290 HUS, Helsinki, Finland \\ ${ }^{2}$ Central Union for the Welfare of the Aged, Malmin kauppatie 26, 00700 Helsinki, Finland \\ ${ }^{3}$ Unit of General Practice, Helsinki University Central Hospital, BOX 20, 00014 University of Helsinki, Helsinki, Finland
}

Correspondence should be addressed to Reijo S. Tilvis, reijo.tilvis@helsinki.fi

Received 30 November 2010; Revised 5 January 2011; Accepted 13 January 2011

Academic Editor: James Lindesay

Copyright (C) 2011 Reijo S. Tilvis et al. This is an open access article distributed under the Creative Commons Attribution License, which permits unrestricted use, distribution, and reproduction in any medium, provided the original work is properly cited.

\begin{abstract}
Background. The harmful associates of suffering from loneliness are still in dispute. Objective. To examine the association of feelings of loneliness with all-cause mortality in a general aged population. Methods. A postal questionnaire was sent to randomly selected community-dwelling of elderly people ( $>74$ years) from the Finnish National Population Register. The questionnaire included demographic characteristics, living conditions, functioning, health, and need for help. Suffering from loneliness was assessed with one question and participants were categorized as lonely or not lonely. Total mortality was retrieved from the National Population Information System. Results. Of 3687 respondents, 39\% suffered from loneliness. Lonely people were more likely to be deceased during the 57 -month follow-up $(31 \%)$ than subjects not feeling lonely $(23 \%, P<.001)$. Excess mortality $(\mathrm{HR}=1.38,95 \% \mathrm{CI}=$ 1.21-1.57) of lonely people increased over time. After controlling for age and gender, the mortality risk of the lonely individuals was $1.33(95 \% \mathrm{CI}=1.17-1.51)$ and after further controlling for subjective health $1.17(\mathrm{CI}=1.02-1.33)$. The excess mortality was consistent in all major subgroups. Conclusion. Suffering from loneliness is common and indicates significant mortality risk in old age.
\end{abstract}

\section{Introduction}

Loneliness is a distressing feeling which has been defined as an individual's subjective experience about lack of satisfying human relationships [1]. The terms loneliness and social isolation have often been used interchangeably but they are distinct concepts [2]. Social isolation refers to the number of individual's social contacts, and can be objectively measured. Loneliness can be evaluated only by the individual experiencing it [2]. In Finland, about one third of older people suffer from loneliness $[3,4]$. Poor functional status, widowhood, living alone, depression, feeling of being poorly understood by close persons, and unfulfilled expectations of contacts with friends have been the most powerful explanations for suffering from loneliness $[4,5]$. Thus, the quality and satisfaction of relationships are more important determinants of loneliness than the actual number of contacts [6-9].

Several studies have addressed the harmful associates of loneliness. Associations have been found with impaired quality of life [10], poor subjective health [11] disability [12], increased use of social and health services [13-16], and risk of cognitive decline $[16,17]$. Consequently, the deleterious effects of loneliness on survival prognosis could be expected but the results have been inconsistent, so far. Social isolation has been proved to increase mortality independently of feelings of loneliness $[18,19]$. In middle-aged men the increased postoperative mortality after coronary by-passing has been associated with low quality of social relationships and feelings of loneliness [20]. Fewer feelings of loneliness have been associated with a reduced mortality risk among older persons living in the Netherlands [21]. In this sample excess mortality was neither explained by the chronic disease status nor lack of social support suggesting that loneliness influences mortality through another pathway than physical health status. Nor did the person's subjective health or health behavior account for the interaction between loneliness and mortality. On the contrary, social support and loneliness have been found to affect indirectly on mortality of the Japanese older people via chronic diseases, functional status, and subjective health [19]. 
In a 10-year followup of 75-, 80-, and 85-year-old citizens of Helsinki, both cognitive decline and mortality were doubled among people feeling lonely [16, 22].

These results prompted us to conduct a nationwide randomized controlled intervention trial aimed at empowering elderly people, and promoting their peer support, and social integration [23]. The intervention group showed a significant improvement in subjective health, better cognition, and significantly lower health care costs during the two-year followup. In addition, the intervention led to a surprisingly clear mortality reduction within 2-year followup.

This surprising result prompted us to retest the association of loneliness with survival prognosis of the whole population sample. The major target was to assess whether and to what extent suffering from loneliness is an indicator of mortality among home-dwelling elderly people.

\section{Methods}

In autumn 2002, a postal questionnaire was sent to random sample of 6,786 Finnish aged ( $\geq 75$ years) people gathered from the Finnish National Population Register, and resent after one month to those who had not yet responded [4, 5]. After removing people living in permanent institutional care $(10.5 \%)$, and people who had died before receiving the questionnaire $(5.1 \%)$, the number of the potential community-dwelling respondents was 5722, of which 4113 returned the questionnaire. The response rate was thus $72 \%$. Approval to conduct the survey was obtained from the local Ethics Committee.

The questionnaire included background information such as age, gender, marital status, education, living conditions, social contacts, physical functioning, subjective health, and subjective need for help. Loneliness was assessed in one question "Do you suffer from loneliness?" (1 = seldom or never, 2 =sometimes, and $3=$ often or always). This question has been used in prior surveys since 1989 and has been found to be easily understandable for older persons [16]. Loneliness was divided using two categories (0 (not lonely) = those who reported feeling lonely seldom or never, and 1 (lonely) = those who suffered from loneliness sometimes and often or always).

Subjective health was asked with the question "What do you consider your current health to be like?" ( $1=$ healthy, $2=$ quite healthy, $3=$ unhealthy and $4=$ very unhealthy). Subjective health was categorized using two groups (0 (good) $=$ those who considered them healthy and quite healthy, 1 (poor)=those who considered them unhealthy or very unhealthy). Poor vision indicated inability to read normal text and poor hearing was defined as an inability to follow normal discussion.

Total mortality up to 30 April, 2007 was retrieved from the National Population Information System, which keeps registry of all Finnish citizens. According to this Register, assessment of vital status is very reliable for people having their permanent residence in Finland (as in the present cohort) irrespective whether they die in Finland or abroad. The assessment of vital status was $100 \%$ complete.

\section{Statistical Methods}

The data were analyzed with the SPSS for Windows statistical program. Lonely respondents were compared to those not feeling lonely with the $X^{2}$-test for categorical variables and with Mann-Whitney $U$ test for age (continuous variable with nonnormal distribution). Independent risks of mortality and the role of feeling lonely in survival time were assessed using the Cox survival analyses, in which age, gender, subjective health and other variables concerning the status of the respondents were forced in as covariates. The Kaplan-Meier curve was used to illustrate the cumulative effect of loneliness on mortality in various subgroups. The respondents who had answered the question about suffering from loneliness were included to the primary analyses $(n=3687)$. The effects of nonresponses $(n=171)$ were tested in sensitivity analyses, in which the nonrespondents were alternatively allocated to the lonely and not-lonely groups.

\section{Results}

4.1. Prevalence and Associates. Mean age of the respondents was 81 and $69 \%$ of them were women. Of the respondents, $38.7 \%$ reported suffering from loneliness always, often, or at least sometimes (Table 1). Loneliness was more common in women than men and was associated significantly for example, with old age, widowhood, lower education, poor health, poor vision and hearing, living in residential care, need for daily help, and inability to go outdoors daily. In the oldest age group (>85 years), 47\% reported suffering from loneliness.

4.2. Predictive Value. Altogether, 967 respondents died within 57-month followup. The all-cause mortality rate of the lonely elderly subjects was $30.8 \%$, whereas that of notlonely was significantly lower $(23.4 \%$, Hazard Ratio $(\mathrm{HR})=$ $1.38, P<.001)$. Of the baseline characteristics differing between the lonely and not lonely individuals, male gender (HR 1.77, $P<.001$ ), age (HR 1.09/year, $P<.001$ ), need for daily help (HR 1.87, $P<.001$ ), poor subjective health (HR 1.51, $P<.001$ ), not having a physical exercise hobby (HR 1.44, $P<.001$ ), and living in residential care (HR 1,26, $P<.001)$ were cumulatively forced into the Cox survival analyses as covariates.

After controlling for age and gender, the mortality risk of the lonely persons was significantly increased (HR 1.33, 95\%CI $=1.17-1.51, P<.001)($ Table 1$)$. The adjusted lifetable analyses revealed that the difference in the surviving rate increased over the follow-up period (Figure 1). The risk (HR 1.17, $P=.023$ ) remained significantly elevated after further controlling for subjective health (Table 2). Controlling for all associates of loneliness (Table 1) abolished the statistical significance of the predictive value of loneliness.

4.3. Consistency of Observations. The subgroup analyses showed that mortality was consistently increased in lonely people of major subgroups (Table 2). The impact of loneliness diminished with deteriorating the subjective health and 
TABLE 1: Baseline characteristics and 57-month mortality by suffering from loneliness.

\begin{tabular}{|c|c|c|c|}
\hline Characteristic & $\begin{array}{l}\text { Not lonely } \\
N=2260\end{array}$ & $\begin{array}{c}\text { Lonely } \\
N=1427\end{array}$ & $P$-value \\
\hline Women, \% & 63.1 & 76.6 & $<.001$ \\
\hline Age, years (range) & 80.8 (70-99) & 81.7 (72-98) & $<.001$ \\
\hline Widowed, \% & 40,5 & 64,5 & $<.001$ \\
\hline $\begin{array}{l}\text { Living in } \\
\text { residential care, \% }\end{array}$ & 5.6 & 10.4 & $<.001$ \\
\hline High education, $\%$ & 39.2 & 30.0 & $<.001$ \\
\hline Poor health, \% & 26.4 & 46,3 & $<.001$ \\
\hline Poor income, \% & 1.5 & 4.8 & $<.001$ \\
\hline $\begin{array}{l}\text { Poor functioning, } \\
\%\end{array}$ & 13.9 & 29.7 & $<.001$ \\
\hline $\begin{array}{l}\text { Goes outdoors } \\
\text { daily, } \%\end{array}$ & 85.0 & 72.9 & $<.001$ \\
\hline $\begin{array}{l}\text { Subjective need for } \\
\text { daily help, \% }\end{array}$ & 19.6 & 36.7 & $<.001$ \\
\hline Poor vision, $\%$ & 5.1 & 10.4 & $<.001$ \\
\hline Poor hearing, \% & 9.8 & 16.3 & $<.001$ \\
\hline $\begin{array}{l}\text { Physical exercise } \\
\text { hobby weekly, \% }\end{array}$ & 67,6 & 55,0 & $<.001$ \\
\hline $\begin{array}{l}\text { Deceased within } 57 \\
\text { months }\end{array}$ & 23,4 & 30.8 & $<.001$ \\
\hline \multicolumn{4}{|c|}{ Hazard ratios of loneliness (95\% confidence intervals) } \\
\hline Unadjusted & 1.00 & $1.38(1.21-1.57)$ & $<.001$ \\
\hline Age and gender & 1.00 & $1.33(1.17-1.51)$ & $<.001$ \\
\hline $\begin{array}{l}\text { Age, gender, and } \\
\text { subjective health }\end{array}$ & 1.00 & $1.17(1.02-1.33)$ & .022 \\
\hline
\end{tabular}

${ }^{1}$ Differences between the groups were tested with $X^{2}$ test for categorical variables, and with Mann-Whitney $U$ test for continuous variables.

was greater in men (age-adjusted HR 1.68, CI $=1.37-2.07$, $P<.001$ ) than women (age-adjusted HR $1.15, \mathrm{CI}=0.98-$ $1.36, P=.083)$. The excess risk of death of the lonely people was most obvious among individuals living in residential care (HR 1.55), not being widowed (HR 1.41), and having a physical exercise hobby (HR 1.37). No subgroup was found, in which the age and gender adjusted hazard ratio were below 1.0.

4.4. Sensitivity Analyses. Because 171 persons did not answer the question about suffering from loneliness, the effects of drop-outs were tested with two-type sensitivity analyses. When the nonrespondents were allocated to the not lonely group, the hazard ratio adjusted for age, gender, and subjective health was $1.17(\mathrm{CI}=1.03-1.34, P=.017)$. When the nonresponders were allocated to lonely, the respective figure was $1.13(\mathrm{CI}=0.99-1.29, P=.059)$.

\section{Discussion}

Although there have been several longitudinal studies showing the adverse effects of loneliness on health and use of health services $[13,15-17,21,23,24]$, this relatively large
TABle 2: Age and gender adjusted 57-month mortality risks of loneliness in selected subgroups.

\begin{tabular}{|c|c|c|c|c|}
\hline Subgroup & $N$ & HR & $95 \% \mathrm{CI}$ & $P$-value \\
\hline Men & 1131 & 1.80 & $1.47-2.21$ & $<.001$ \\
\hline Women & 2556 & 1.30 & $1.11-1,53$ & $<.001$ \\
\hline$<85$ years & 2884 & 1.31 & $1,12-1.55$ & $<.001$ \\
\hline$\geq 85$ years & 803 & 1,23 & $1.01-1,51$ & .043 \\
\hline Good health & 2381 & 1,31 & $1.09-1.59$ & .004 \\
\hline Poor health & 1231 & 1.07 & $0.89-1.28$ & .471 \\
\hline Daily need for help & 947 & 1.18 & $0.98-1.44$ & .087 \\
\hline No daily need for help & 2700 & 1.13 & $0.93-1.36$ & .217 \\
\hline Widowed & 1826 & 1.32 & $1,10-1.57$ & .003 \\
\hline Not widowed & 1861 & 1.41 & $1,16-1.71$ & $<.001$ \\
\hline Living at home & 3319 & 1.22 & $1.06-1,41$ & .006 \\
\hline $\begin{array}{l}\text { Living in residential } \\
\text { care }\end{array}$ & 326 & 1.55 & $1.10-2.18$ & .013 \\
\hline Goes outdoors daily & 3053 & 1.18 & $0.99-1,39$ & .057 \\
\hline $\begin{array}{l}\text { Does not go outdoors } \\
\text { daily }\end{array}$ & 726 & 1.34 & $1.08-1.67$ & .008 \\
\hline $\begin{array}{l}\text { Physical exercise } \\
\text { hobby }\end{array}$ & 2332 & 1.37 & $1.13-1.67$ & $<.001$ \\
\hline $\begin{array}{l}\text { No physical exercise } \\
\text { hobby }\end{array}$ & 1363 & 1.14 & $0.95-1.36$ & .165 \\
\hline
\end{tabular}

study confirms that one simple question unveils over 30percentage excess mortality risk of an aged population. Since the increased mortality was not restricted to any particular subgroup, the consistency of observation emphasizes the importance and validity of the finding.

The cross-sectional association analyses do not indicate any causal relationships between loneliness and other prognostic significant conditions (Table 1). Widowhood, accumulating losses in old age, poor health and functioning, and living conditions may cause loneliness $[4,5]$. Furthermore, both suffering from loneliness and its associates may be caused by other factors not tested in this study. The lack of in-depth interviews, clinical examinations including assessments of comorbidity, and cross-sectional data except mortality are the major weaknesses of the nationwide survey handicapping the reliable evaluation of causes and consequences of loneliness. It is possible that suffering from loneliness is not a mere risk indicator but a real risk factor in old age. In fact, psychosocial group intervention in our study population improved health, delayed cognitive decline, reduced all-cause mortality, and diminished the use of health care services of the participants [23].

The associations of loneliness with mortality seemed to diminish with deteriorating the subjective health suggesting the emerging importance of diseases in old age. The subjective health has been suggested to be sensitive and comprehensive measure of general health status and significant predictor of mortality [25]. Subjective health has a biological basis showing a graded association, for example, with laboratory values, and it covers a broad spectrum of health conditions [25]. Although the association 


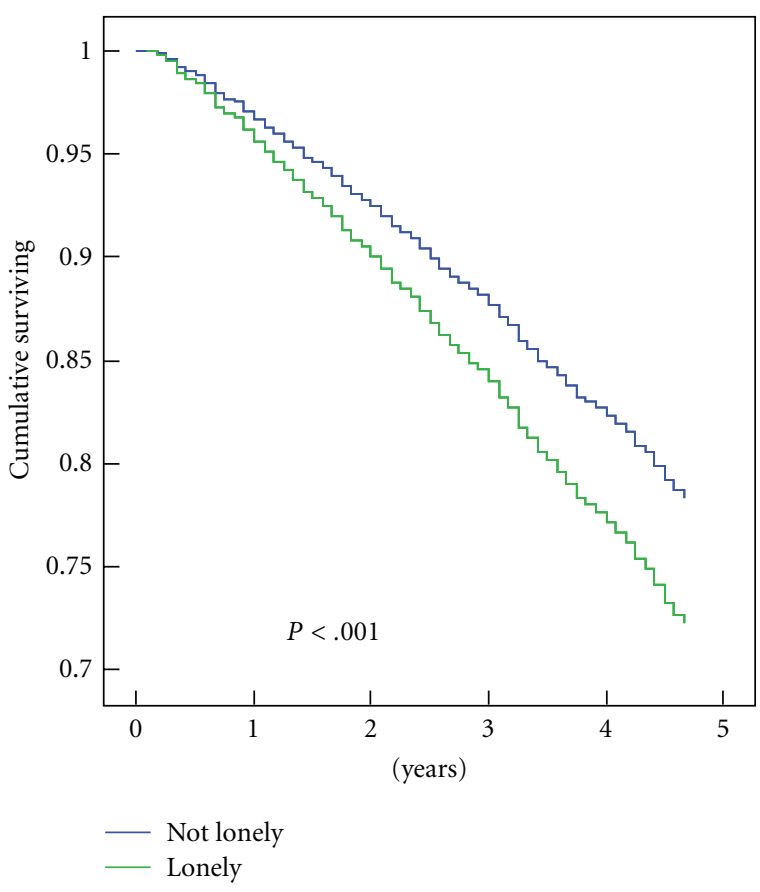

FIGURE 1: Cumulative surviving adjusted for age and gender by suffering from loneliness $(P<.001)$.

between loneliness and mortality seemed to diminish with deteriorating health, it remained significant after controlling for subjective health suggesting that the excess mortality was not explained by illnesses alone.

Most importantly, the excess mortality of lonely people adjusted for age, gender, and subjective health increased continually with the passing of time suggesting that suffering from loneliness is not merely a consequence of acute changes in the health and living conditions but may aggravate mechanisms leading to impaired long-term survival prognosis. It is conceivable that controlling for all possible associates, for example, need for daily help, dwelling, and weekly physical exercise hobbies, gradually abolished the statistical significance of the predictive value of loneliness. These associates themselves were strong risk indicators in the present population sample. Apart from age and gender, subjective need for daily help appeared to be both the closest associate of loneliness and most powerful confounder in the survival analyses. To some extent, both issues may indicate unfulfilled expectations to other people and society.

Earlier analyses of the present sample have shown that feelings of loneliness were not associated with social isolation or lesser quantities of contacts but were associated with expectations of social contacts and experienced quality of relationships $[4,5]$. Consequently, the results support the view that loneliness, a risk indicator independent of social nets and contacts, is, at least partly, a reflection of inner negative feelings and general attitudes toward life [24]. In this respect, the observation about the close relationship between need for help and suffering from loneliness is of particular interest. This result also helps to understand surprisingly clear positive treatment effects of the psychosocial group interventions on selected voluntary persons of this population sample [23].

Interestingly, suffering from loneliness had a more powerful effect on survival in men than women. Whilst older men expressed suffering from loneliness less often than women, they experienced more harmful associates of loneliness. This observation supports the view that the threshold for feeling lonely is lower in women than men or that women admit easier their feelings of loneliness and may have more expectations for satisfying social contacts $[6,11]$. The present new finding raises questions about whether the intensity of loneliness or stress reactions caused by loneliness is stronger in men than women.

\section{References}

[1] L. Andersson, "Loneliness research and interventions: a review of the literature," Aging and Mental Health, vol. 2, no. 4, pp. 264-274, 1998.

[2] G. C. Wenger, R. Davies, S. Shahtahmasebi, and A. Scott, "Social isolation and loneliness in old age: review and model refinement," Ageing and Society, vol. 16, no. 3, pp. 333-358, 1996.

[3] M. Jylhä and J. Jokela, "Individual experiences as cultural-a cross-cultural study on loneliness," Ageing Society, vol. 10, pp. 295-315, 1990.

[4] N. Savikko, P. Routasalo, R. S. Tilvis, T. E. Strandberg, and K. H. Pitkälä, "Predictors and subjective causes of loneliness in an aged population," Archives of Gerontology and Geriatrics, vol. 41, no. 3, pp. 223-233, 2005.

[5] P. E. Routasalo, N. Savikko, R. S. Tilvis, T. E. Strandberg, and K. H. Pitkälä, "Social contacts and their relationship to loneliness among aged people - a population-based study," Gerontology, vol. 52, no. 3, pp. 181-187, 2006.

[6] S. Berg, D. Mellstrom, G. Persson, and A. Svanborg, "Loneliness in the Swedish aged," Journals of Gerontology, vol. 36, no. 3, pp. 342-349, 1981.

[7] R. F. Creecy, W. E. Berg, and R. Wright, "Loneliness among the elderly: a causal approach," Journals of Gerontology, vol. 40, no. 4, pp. 487-493, 1985.

[8] L. C. Mullins and E. Dugan, "The influence of depression, and family and friendship relations, on residents' loneliness in congregate housing," Gerontologist, vol. 30, no. 3, pp. 377-384, 1990.

[9] O. Kim, "Predictors of loneliness in elderly Korean immigrant women living in the United States of America," Journal of Advanced Nursing, vol. 29, no. 5, pp. 1082-1088, 1999.

[10] U. Jakobsson and I. R. Hallberg, "Loneliness, fear, and quality of life among elderly in Sweden: a gender perspective," AgingClinical and Experimental Research, vol. 17, no. 6, pp. 494-501, 2005.

[11] M. A. R. Tijhuis, J. De Jong-Gierveld, E. J. M. Feskens, and D. Kromhout, "Changes in and factors related to loneliness in older men. The Zutphen Elderly Study," Age and Ageing, vol. 28, no. 5, pp. 491-495, 1999.

[12] M. I. Bisschop, D. M. W. Kriegsman, T. G. van Tilburg, B. W. J. H. Penninx, J. TH. M. van Eijk, and D. J. H. Deeg, "The influence of differing social ties on decline in physical functioning among older people with and without chronic diseases: the longitudinal aging study Amsterdam," AgingClinical and Experimental Research, vol. 15, no. 2, pp. 164-173, 2003. 
[13] D. W. Russell, C. E. Cutrona, A. De la Mora, and R. B. Wallace, "Loneliness and nursing home admission among rural older adults," Psychology and Aging, vol. 12, no. 4, pp. 574-589, 1997.

[14] A. Ellaway, S. Wood, and S. Macintyre, "Someone to talk to? The role of loneliness as a factor in the frequency of GP consultations," British Journal of General Practice, vol. 49, no. 442, pp. 363-367, 1999.

[15] J. Geller, P. Janson, E. McGovern, and A. Valdini, "Loneliness as a predictor of hospital emergency department use," Journal of Family Practice, vol. 48, no. 10, pp. 801-804, 1999.

[16] R. S. Tilvis, K. H. Pitkala, J. Jolkkonen, and T. E. Strandberg, "Social networks and dementia," Lancet, vol. 356, no. 9223, pp. 77-78, 2000.

[17] L. Fratiglioni, S. Paillard-Borg, and B. Winblad, "An active and socially integrated lifestyle in late life might protect against dementia," Lancet Neurology, vol. 3, no. 6, pp. 343-353, 2004.

[18] L. F. Berkman and S. L. Syme, "Social networks, host resistance, and mortality: a nine-year follow-up study of Alameda County residents," American Journal of Epidemiology, vol. 109, no. 2, pp. 186-204, 1979.

[19] H. Sugisawa, J. Liang, and X. Liu, "Social networks, social support, and mortality among older people in Japan," Journals of Gerontology, vol. 49, no. 1, pp. S3-S13, 1994.

[20] G. A. Kaplan, T. W. Wilson, R. D. Cohen, J. Kauhanen, M. Wu, and J. T. Salonen, "Social functioning and overall mortality: prospective evidence from the Kuopio Ischemic Heart Disease Risk Factor Study," Epidemiology, vol. 5, no. 5, pp. 495-500, 1994.

[21] B. W. J. H. Penninx, T. Van Tilburg, D. M. W. Kriegsman, D. J. H. Deeg, A. J. P. Boeke, and J. TH. M. Van Eijk, "Effects of social support and personal coping resources on mortality in older age: the longitudinal aging study Amsterdam," American Journal of Epidemiology, vol. 146, no. 6, pp. 510-519, 1997.

[22] R. S. Tilvis, M. H. Kähönen-Väre, J. Jolkkonen, J. Valvanne, K. H. Pitkala, and T. E. Strandberg, "Predictors of Cognitive Decline and Mortality of Aged People over a 10-Year Period," Journals of Gerontology-Series A Biological Sciences and Medical Sciences, vol. 59, no. 3, pp. 268-274, 2004.

[23] K. H. Pitkala, P. Routasalo, H. Kautiainen, and R. S. Tilvis, "Effects of psychosocial group rehabilitation on health, use of health care services, and mortality of older persons suffering from loneliness: a randomized, controlled trial," Journals of Gerontology-Series A Biological Sciences and Medical Sciences, vol. 64, no. 7, pp. 792-800, 2009.

[24] M. Jylhä, S. Volpato, and J. M. Guralnik, "Self-rated health showed a graded association with frequently used biomarkers in a large population sample," Journal of Clinical Epidemiology, vol. 59, no. 5, pp. 465-471, 2006.

[25] K. H. Pitkala, M. L. Laakkonen, T. E. Strandberg, and R. S. Tilvis, "Positive life orientation as a predictor of 10year outcome in an aged population," Journal of Clinical Epidemiology, vol. 57, no. 4, pp. 409-414, 2004. 


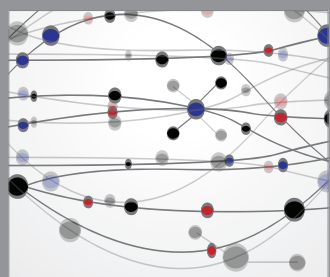

The Scientific World Journal
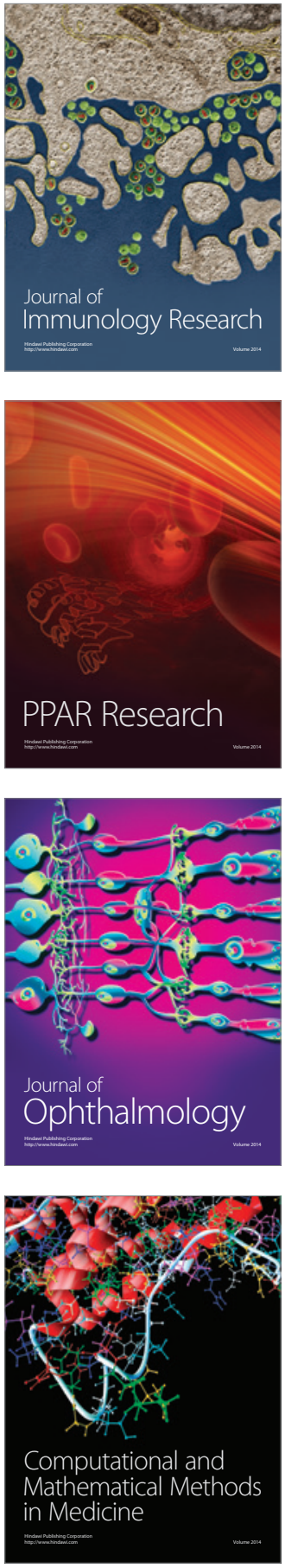

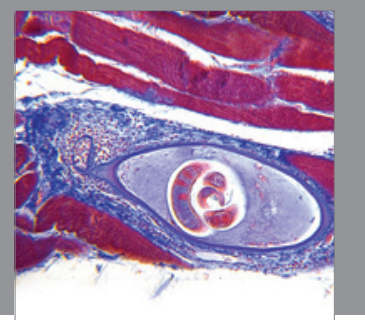

Gastroenterology

Research and Practice
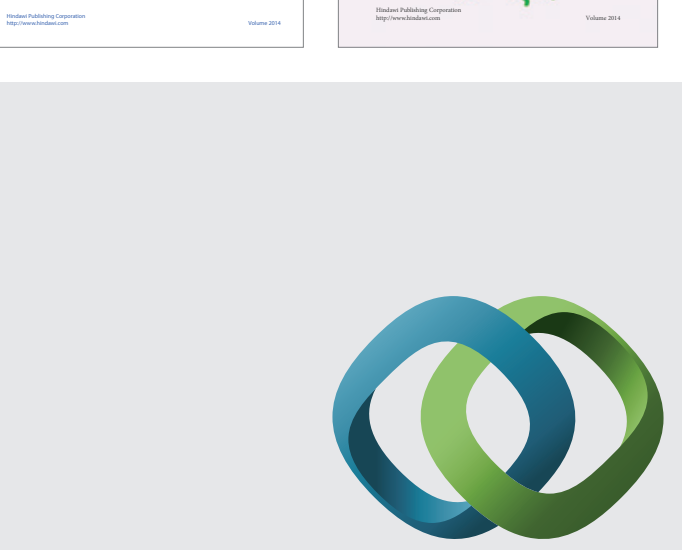

\section{Hindawi}

Submit your manuscripts at

http://www.hindawi.com
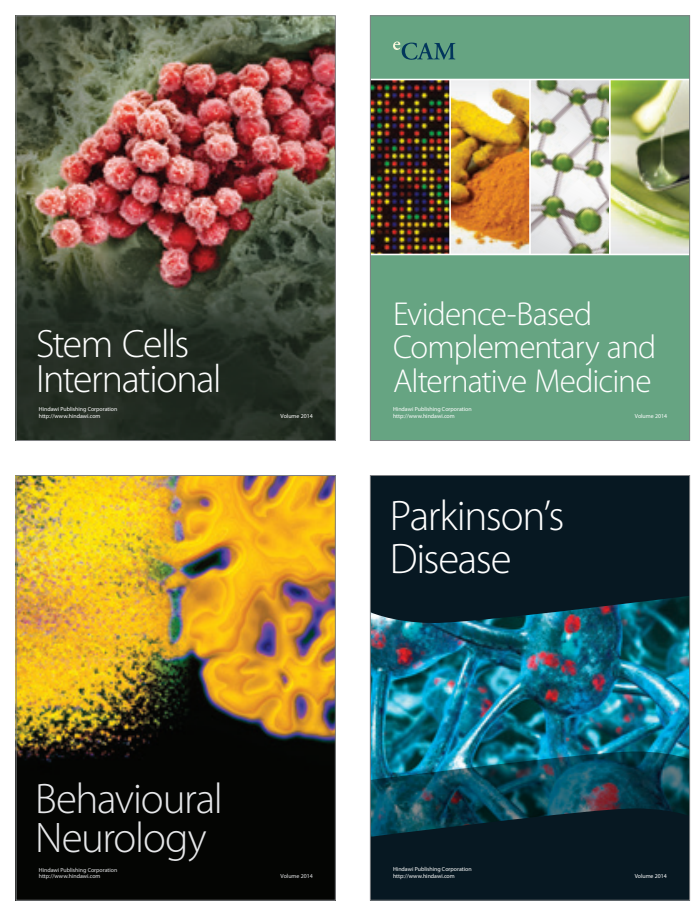

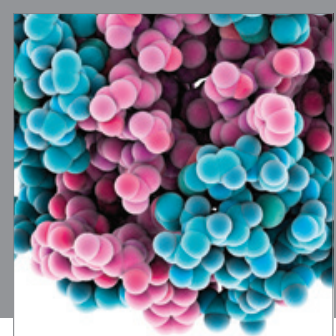

Journal of
Diabetes Research

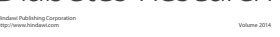

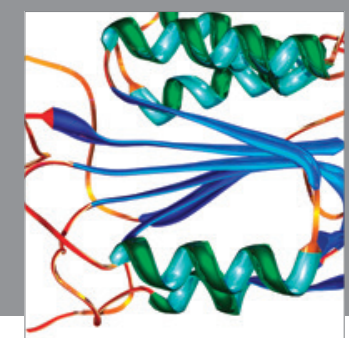

Disease Markers
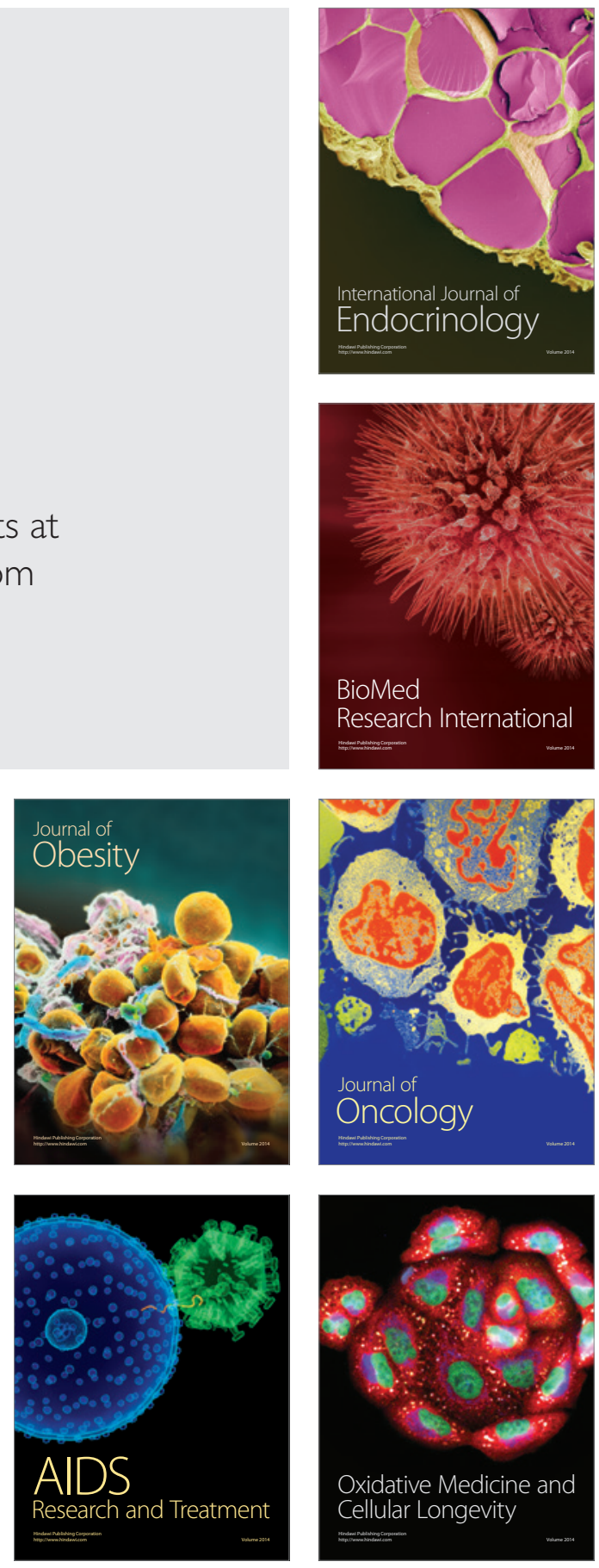